International Journal of Innovation Management

Vol. 20, No. 7 (October 2016) 1650067 (27 pages)

(C) World Scientific Publishing Europe Ltd.

DOI: $10.1142 /$ S1363919616500675

\title{
CULTURAL CONTINGENCIES OF OPEN INNOVATION STRATEGIES
}

\author{
ACHIM HECKER \\ Department of Business Administration \\ Private University Seeburg Castle \\ Seeburgstraße 8, A-5201 Seekirchen am Wallersee \\ Salzburg, Austria \\ achim.hecker@uni-seeburg.at
}

Published 28 April 2016

\begin{abstract}
This study draws on a sample of 49,919 firms from 13 countries to investigate the impact of national culture on the performance of inbound open innovation strategies. The study first validates the curvilinear relationships of external search breadth and depth with innovation performance, as first established by Laursen and Salter (2006) [Laursen, K and A Salter (2006). Open for innovation: The role of openness in explaining innovation performance among U.K. manufacturing firms. Strategic Management Journal, 27(2), 131-150] controlling for a number of country-specific factors including culture and the institutional environment. The study then draws on Hofstede's cultural framework to theoretically and empirically investigate the influence of a country's culture on the effectiveness of firms' search strategies. The results show that cultural factors not only directly impact innovation performance, but also interact with search breadth and depth, thereby moderating the success of inbound open innovation strategies.
\end{abstract}

Keywords: Country culture; innovation; open innovation; national culture; search strategies.

JEL Classifications M14, M16, O32

\section{Introduction}

The innovation strategies of many firms are presently undergoing fundamental changes to become increasingly open and collaborative. More and more firms use external knowledge providers to bolster their internal R\&D capabilities and to improve and sustain innovation performance (Rigby and Zook, 2002; Tether and

I would like to thank my research assistant Alois Ganter for his excellent support. 
Tajar, 2008). In their effort to keep pace with an increasingly dynamic environment, they search more broadly for external knowledge sources and integrate external innovation partners more deeply in their R\&D activities (Chesbrough, 2003; van de Vrande et al., 2009).

A substantial body of scholarly research reflects this trend as a shift from a closed to an open innovation model (e.g., Chesbrough, 2003; Barge-Gil, 2010, 2013; Dahlander and Gann, 2010; Enkel et al., 2009; Gassmann et al., 2010; Lichtenthaler, 2011; Tomlinson, 2010; van de Vrande et al., 2010). Recent studies on open innovation shed light on a broad range of topics, such as performance implications stemming from different degrees of openness and the breadth and depth of firm's external search efforts (e.g., Barge-Gil, 2013; Laursen and Salter, 2006), the density and extent of maintained R\&D networks (e.g., Ahuja, 2000), the governance mode of external relations (e.g., Fey and Birkinshaw, 2005; van de Vrande et al., 2006), or the relationship between the extent and form of external innovation relations and the structure of the industrial knowledge base (Aslesen and Freel, 2012). Nevertheless, recent surveys of this fast-growing field of literature still point to significant gaps in achieving a comprehensive understanding of this new paradigm (Dahlander and Gann, 2010; Gassmann, 2006; van de Vrande et al., 2010; Huizingh, 2011; Lichtenthaler, 2011). In particular, these gaps pertain to the contingencies of open innovation strategies and their performance implications (e.g., Foss et al., 2011; Lichtenthaler, 2011). Studies on the relationship between the openness and outcome of firms' innovation activities have rendered inconclusive results ( $c f$. the survey by Barge-Gil, 2013), pointing to the moderating influence of context factors not accounted for yet. According to Huizingh (2011:2) "[t]he context dependency of open innovation is one of the least understood topics."

This study addresses the gap in current research by investigating country culture as a contingency of inbound open innovation strategies. Although the general impact of cultural factors on firms' innovation behaviour is well established (e.g., Hayton et al., 2002; Jones and Davis, 2000; Png and Tan, 2001; Shane, 1993; van Everdingen and Waarts, 2003; Tellis et al., 2009), we know of only one study by Herzog and Leker (2010), researching cultural requirements of open versus closed innovation strategies. That study, however, focuses on corporate, as opposed to national culture, and examines only three business units of a single firm instead of drawing on a large sample of diverse firms. Furthermore, this work merely assesses the prevalence of a small set of specific cultural attitudes in innovating business units without measuring their actual effects on innovative performance.

My study, in contrast, pursues the following research question: "What influence has national culture on the effectiveness of inbound open innovation strategies?" To investigate this question, we build on the seminal contribution of Laursen and Salter (2006). Laursen and Salter were among the first to quantitatively research 
the role of openness as a factor explaining innovation performance. They introduce measures for breadth and depth of a firm's external knowledge search and empirically prove the curvilinear relationships between these measures and the firm's innovation performance. As their empirical investigation is confined to a sample of UK manufacturing firms, however, it remains unclear to what extent their results hold true for different countries, cultures, and institutional contexts. Specifically, due to lacking variance, Laursen and Salter (2006) are unable to account for effects of national culture on the effectiveness of open innovation strategies.

Our study extends current knowledge precisely in these regards. We first validate Laursen and Salter's (2006) results using a sample of 49,919 firms from 13 countries, controlling for a number of country-specific factors including a country's culture and institutional environment. Drawing on the cultural framework first established by Hofstede in 1980 and significantly elaborated upon by subsequent works (e.g., Hofstede, 2001; Kirkman et al., 2006), we then theoretically consider and empirically investigate the influence of various cultural dimensions on the effectiveness of firms' search strategies.

Besides contributing to the open innovation literature, this study helps fill two gaps in cross-cultural management research emphasised by several recent surveys (Gelfand et al., 2007; Kirkman et al., 2006; Leung et al., 2005). First, "research in cross-cultural OB [i.e., organizational behavior] still focuses largely on cultural main effects and ignores situational factors as main effects or moderators. (...) For example, cross-level research that examines how cultural values at the national level interact with organizational context factors to predict unit-level processes or outcomes, (...) is a needed wave of the future." (Gelfand et al., 2007:496). According to our knowledge, no currently published study has theoretically elaborated or empirically examined moderating effects of national culture on firmlevel innovation conduct and performance. By investigating the interplay between national culture and a firm's strategic context in shaping innovative success we hope to contribute to this new wave of cross-cultural management research.

Second, criticisms have been voiced concerning the fact that most extant research efforts in this field focus selectively on one or two cultural dimensions (with the bulk of studies exclusively occupied with individualism versus collectivism) to explain cross-cultural differences in organisational behaviour (Gelfand et al., 2007). Our study, in contrast, includes all established Hofstede dimensions of country culture.

The remainder of the paper is organised as follows. The next section develops a theoretical perspective and derives hypotheses about the impact of country culture on the effectiveness of inbound open innovation strategies. The subsequent section introduces methods and data of the empirical investigation, and tests the hypotheses. The final section discusses the findings, derives theoretical, managerial, 
and political implications, and concludes by pointing to some limitations found in the analysis.

\section{Theoretical Development}

\section{The relationships between external search breadth and depth and the innovation performance}

Laursen and Salter (2006) investigate the impact of a firm's search strategy for external knowledge on innovative performance. To this aim, the authors develop the two concepts of search breadth and search depth characterising a firm's innovative openness. By theoretical reasoning and empirical investigation, they link both concepts to a firm's ability to successfully develop and commercialise products of different levels of novelty.

Search breadth depicts the variety of external knowledge sources (such as customers, users, suppliers, universities, and other institutions inside the innovation system) a firm relies on to bolster its R\&D activities. With widening search breadth, firms increase their chance of finding relevant knowledge and encountering valuable innovation opportunities. Efficiently assimilating knowledge from external sources, however, often requires building close relationships, including institutionalised ways of interaction and an atmosphere of trust. Innovation success thus not only depends on the breadth, but also on the depth - defined as the number of external knowledge sources and innovation partners a firm integrates deeply into its innovation processes - of search activities.

The integration of external knowledge sources (and in particular their deep integration) consumes a firm's absorptive capacity and managerial attention. If these scarce resources are spread to thinly across different knowledge sources, their exploitation becomes less efficient. This implies that benefits accruing from search breadth and depth are subject to decreasing returns and that from a certain point onwards firms' additional search intensity may be rendered unproductive. In consequence, Laursen and Salter (2006) hypothesise curvilinear (inverted U-shape) relationships between innovation performance and search breadth and depth, respectively. Drawing on a sample of UK manufacturing firms, they corroborate the predicted relationships with empirical evidence.

Laursen and Salter (2006) do not explicitly consider and control for the influence of country-specific contingencies such as cultural or institutional factors. As we will argue in the following, national culture certainly has an influence on the assimilation and integration of knowledge from external sources into a firm's innovation processes and therefore affects the balance between the conducive and obstructive effects of external search breadth and depth on innovation 
performance. This influence, however, only shifts the tipping point of the curvilinear relationship and does not dispense with its curvilinearity altogether, as Laursen and Salter's (2006) basic arguments can reasonably be expected to hold across varying countries, cultures, and institutional environments. This leads to the following generalisations of their original hypotheses.

Hypothesis 1a: External search breadth is curvilinearly related to innovative performance independent of a country's culture and institutional environments. Hypothesis 1b: External search depth is curvilinearly related to innovative performance independent of a country's culture and institutional environments.

\section{The influence of national culture on the effectiveness of external search breadth and depth}

National culture is commonly defined as a set of values and beliefs shared by a country's citizens that shapes social institutions and guides individual behaviour and action (Hayton et al., 2002; Hofstede, 1980; House et al., 2004; Tsui et al., 2007). National culture represents a multifarious and elusive concept. Several attempts have been undertaken to dissect and systematise its facets and dimensions. Hofstede (1980) provides the best established framework, which has since been extensively tested and elaborated. Most studies scrutinising the relationship between national culture and innovation activity use this framework as a conceptual underpinning (e.g., Hayton et al., 2002; Jones and Davis, 2000; Nakata and Sivakumar, 1996; Png and Tan, 2001; Shane, 1993; Shane et al., 1995; Steensma et al., 2000a; Tellis et al., 2009; van Everdingen and Waarts, 2003).

The application of that framework to the research question of this study therefore allows consistency and comparability with these studies, and thus for cumulative knowledge building. In contrast to alternative accounts, Hofstede's cultural measures are explicitly based on work-related values, making them particularly suitable for researching firm-related innovation behaviour (Hayton et al., 2002; Steenkamp et al., 1999). Although Hofstede's framework has been criticised for not rendering a complete picture of all facets of a country's culture, there is a substantial body of research corroborating the relevance and validity of the considered cultural dimensions for managerial decision-making and firm behaviour (Kirkman et al., 2006; Leung et al., 2005). For these reasons, we use this framework as analytical lens for our study.

Originally, Hofstede's framework comprised four dimensions: power distance, uncertainty avoidance, individualism, and masculinity (Hofstede, 1980). Later, long-term orientation was added as a fifth dimension (Hofstede, 2001; Hofstede et al., 2010). In the following, we succinctly characterise the five dimensions of 
Hofstede's culture concepts ( $c f$. Hofstede et al., 2010, for an extended discussion) before we consider their relation to firm innovation behaviour and, in particular, to the effectiveness of inbound open innovation strategies:

- Masculinity refers to gender differences in personal values. Hofstede (1980; 2001) shows that women across all countries largely accord in cherishing specific values and attitudes such as modesty, solidarity, solicitousness, and caring. In countries scoring low on Hofstede's masculinity index, men are more likely to also espouse these feminine values. By contrast, in countries exhibiting a high masculinity index men embrace the opposing values such as decisiveness, assertiveness, competitiveness, and ambition. Furthermore, masculine cultures place greater emphasis on material values, output, performance, rewards, and recognition; feminine cultures hold modality, personal relations, harmonic co-existence, and quality of life in high esteem.

- Individualism describes the relationship between the individual and the ingroup (e.g., workforce, and department). Individualistic cultures emphasise personal autonomy and achievement, as well as individual rights. People are independent to choose their way of life, way of working, and their affiliations. In cultures scoring low on the individualism dimension, people are closely integrated into their in-groups. They are expected to conform to the group's norms and customs, and to subordinate personal interest to the collective interest. Such collectivistic cultures also prefer collective over individual decision-making.

- Power distance describes the extent to which inequality in the distribution of power is accepted and expected in a society or organisation particularly by the underprivileged, those on the low end of the power scale. In the context of the workplace, a low power distance goes along with the appreciation and expectation of a high degree of employee participation in decision-making, information sharing across hierarchies, and a consultative leadership style. Cultures that endorse a high power distance, in contrast, usually exhibit more centralised decision structures, rely on formal rules and positions, and accept an autocratic or paternalistic leadership style.

- Uncertainty avoidance measures a society's tolerance for uncertainty and ambiguity. People in cultures with low uncertainty avoidance are more comfortable in fluid situations and dynamic environments, they embrace change as chance of improvement. High scores on uncertainty avoidance, in contrast, reflect a society's uneasiness with ambiguous and unstructured situations. Excessive planning, fixed rules and standardised procedures, contingency plans, and security measures are widely used strategies to reduce uncertainty and ambiguity in those societies. 
- Long-term orientation describes a society's time horizon and its relationship to the past and future. Short-term oriented cultures emphasise values related to the past and the status quo, such as steadiness, preservation of the heritage, and respect for the tradition. Long-term oriented societies, on the other hand, are well disposed to adapt to new circumstances, and focus on future events and results. They attach more importance to forward-looking virtues such as pragmatism, persistence, and thrift.

So far, studies investigating the impact of national culture on innovation have treated culture as an independent variable and primarily focus on main effects type I studies according to the classification of Tsui et al. (2007). They consistently show a negative relationship between uncertainty avoidance and innovation performance; results concerning other dimensions' impact are more ambiguous (e.g., Hayton et al., 2002; Jones and Davis, 2000; Png and Tan, 2001; Shane, 1993; van Everdingen and Waarts, 2003).

According to our knowledge, there are currently no type II studies, i.e., studies undertaking a theoretical elaboration or empirical examination of moderating effects of national culture on innovation behaviour and, in particular, of the impact of these cultural dimensions on the effectiveness of a firm's open innovation strategies. There are, however, a few related type I studies researching the main effects of attitudes of entrepreneurs and firms from different societies on their cooperative strategies. Steensma et al. (2000b) thus show that entrepreneurs from feminine societies have a greater appreciation for the strategic importance of cooperation in general, and place greater emphasis on fostering relationships that go beyond negotiating contractual safeguards. Steensma et al. (2000a), in addition, find that masculinity scores are directly linked to technology alliance formation such that a country's level of masculinity has a detrimental effect on the propensity of small, independent manufacturing firms in that country to cooperate with other firms for technological innovation.

Although these studies focus on the main effects and culture as predictor of firm's inclination to cooperate, they also allow drawing conclusion on the success and effectiveness of existing cooperations. Consistent with Hofstede's (2001) conceptual reasoning, masculine societies place emphasis on assertiveness and competitive behaviour. They tend to attribute success to singular actors and legitimise the pursuit of self-interest at the expense of the common good. Masculinity thus encourages self-serving attitudes that impede close collaboration and reciprocal cooperation. Feminine cultures, on the other hand, esteem cooperative values and mutual gains, showing a strong preference for maintaining interpersonal relationships and resolving conflict through negotiation and compromise (Hofstede, 2001). Working from this background and with the recognition that a 
win-win orientation and the focus on relational benefits and mutual trust are important requisites for knowledge exchange and cooperation effectiveness (Dyer and Singh, 1998), we surmise that broad and deep cooperative innovation arrangements are more successful in more feminine cultures.

Hypothesis 2a: The more feminine a culture, the more effective external search breadth will be in influencing innovative performance.

Hypothesis 2b: The more feminine a culture, the more effective external search depth will be in influencing innovative performance.

Cooperative relations to external knowledge sources and innovation partners should also benefit from a collectivistic cultural orientation. Collective cultures foster the close integration of peers and partners into a cohesive in-group pursuing a common goal. They instill collective norms supporting cooperation and the coordination of members' decentralised actions. Goal congruency and shared norms constitute a strong form of trust, enhancing collaborative performance (Barney and Hansen, 1994). The attitudes, values, and beliefs cherished by collective cultures furthermore facilitate the development of a common identity, group accountability, and communication which are central mechanisms for enhancing cooperative effectiveness (Chen et al., 1998). Individual cultures, in contrast, stress personal goals and gains over the collective good. They put emphasis on independence and autonomy, and resist subordination under collective norms governing collaboration.

Several empirical studies underscore the positive impact of a collectivistic over individualistic orientation on cooperative effectiveness. Earley (1989) shows in an experimental setting that collectivistic beliefs reduce social loafing and foster the performance of work groups. Cox et al. (1991) demonstrate that work groups composed of people from collectivist cultures display more cooperative behaviour than those from individualistic cultures. Further studies evidence a cooperative effectiveness to be more pronounced within more strongly perceived in-groups, such as might be constituted by an institutionalized R\&D cooperation (Chen and Li, 2005; Gelfand et al., 2007). The study by Alexander (2012) also supports the beneficial effect of a country's level of collectivism on inter-firm collaboration and shows that lower levels of individualism reduce relational risks in non-equity contractual alliances leading to higher levels of innovation.

Together, theoretical arguments and empirical studies point to the fact that members of more collectivistic cultures are not only more willing to pursue cooperative innovation arrangements but also more successful in leveraging such cooperation to transform external knowledge search into innovation performance. 
Hypothesis 3a: The more collectivistic a culture, the more effective external search breadth will be in influencing innovative performance.

Hypothesis 3b: The more collectivistic a culture, the more effective external search depth will be in influencing innovative performance.

The cultural dimension of power distance is related to the degree of employee participation, (de)centralisation of decision rights, information sharing across hierarchies, degree of formalisation, and leadership styles (Hofstede, 2001). Recently, Foss et al. (2011) investigated the impact of these organisational design parameters on the effectiveness of open innovation strategies. They argue that employee participation, increased information sharing, the delegation of responsibility and decision rights, and other practices related to or involving the implementation of teamwork enable and motivate employees to better identify, assimilate, and exploit knowledge from external knowledge source (customers and users in their study). These practices thereby strengthen both outward- and inward-looking absorptive capacity (Cohen and Levinthal, 1990). Their study empirically shows that customer and user knowledge is leveraged more effectively when such practices are in place. In fact, the effect of customer integration on innovation performance proves to be completely mediated by the existence of these practices (such that without their implementation no significant effect was traceable).

While Foss et al. (2011) focus solely on the involvement of customers and users in the innovation processes, the underlying reasoning arguably carries over to the interaction with other external knowledge sources. R\&D cooperations with suppliers, universities, complementators, etc. should likewise benefit from the increased outward- and inward-looking absorptive capacity brought about by employee participation, intense information sharing across departments and hierarchical levels, and more decentralised decision structures. As these organisational practices are supported by low levels of power distance, we expect that firms rooted in cultures with lesser power distance should derive a higher benefit from the broad and deep involvement of external knowledge sources in innovation activities.

Hypothesis 4a: The less power distant a culture, the more effective external search breadth will be in influencing innovative performance.

Hypothesis 4b: The less power distant a culture, the more effective external search depth will be in influencing innovative performance.

Regarding the remaining two cultural dimensions, uncertainty avoidance and long-term orientation, no clear predictions arise from the theoretical reasoning. Steensma et al. (2000a) establish a positive influence of uncertainty avoidance on 


\section{A. Hecker}

technology alliance formation, as it allows the sharing of risks inherent in $R \& D$ activities, thereby decreasing perceived uncertainty. While recognising the relationship of this dimension to the formation of technology alliance, however, there is no theoretically backed prediction as to the effect of uncertainty avoidance on the success of such technology alliances and open innovation strategies in general. Moreover, the relational risks entailed in collaborative $\mathrm{R} \& \mathrm{D}$ arrangements may compensate the risk-attenuating effects of joint investments.

Regarding long-term orientation, one could argue that it reduces relational risks, as more forward-looking cultures have a stronger inclination to value long-term cooperative gains over short-term defection benefits. Short-term oriented cultures, on the other hand, emphasise steadiness and stability of personal relations, reciprocation in social interaction, and the preservation of the status quo (Hofstede, 2001). As these latter aspects likewise serve to stabilise cooperative arrangements, no clear prediction arises as to the bearing of long-term orientation on the effectiveness of external knowledge sourcing.

Finally, the extant literature and theoretical reasoning do not suggest a systematic relationship between the degree of novelty of an innovation and the cultural dimensions' impact on innovation performance. Therefore, although our empirical investigation differentiates innovation performances into radical innovations (new-to-the-market) and incremental innovations (just newto-the-firm), we expect these predicted relationships to hold for both types of innovation.

Figure 1 presents the research model summarising the hypotheses derived from the theoretical discussion.

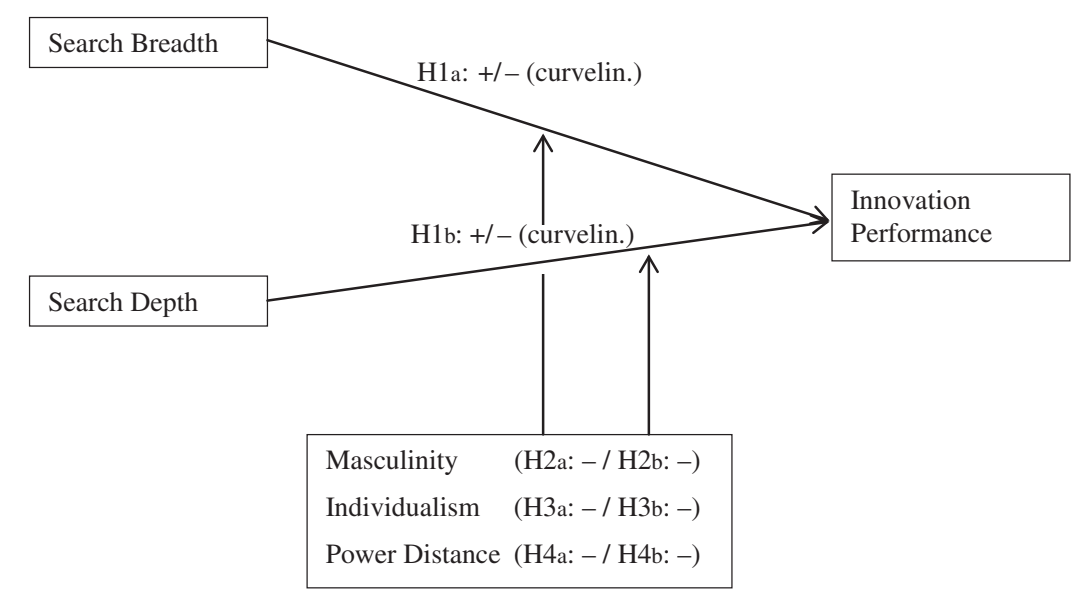

Fig. 1. Research model + positive effect, - negative effect, + /- (curvelin.), inverted u-shaped relationship. 


\section{Empirical Investigation}

\section{Sample and measures}

For the empirical analysis, we pool the samples of 13 European countries from the Community Innovation Survey (CIS) 2008 and obtain a sample consisting of 49,919 firms based in Bulgaria (BG), Czech Republic (CZ), Germany (DE), Estonia (EE), Spain (ES), France (FR), Hungary (HU), Italy (IT), Netherlands (NL), Portugal (PT), Romania (RO), Slovenia (SI), and Slovakia (SK). This selection of countries is constrained by the availability of country-specific CIS data from Eurostat. The CIS is conducted by the national statistical offices in collaboration with Eurostat. The national statistical authorities carry out the data collection as a combination of census and stratified random sampling. The sample is stratified by the size class of enterprises (measured by number of employees), by classification of economic activities (according to NACE Rev. 2), and by region (according to NUTS II). Included are enterprises with 10 or more employees belonging to the sectors B-M of NACE Rev. 2 (i.e., mining and quarrying; manufacturing; supply of electricity, gas, steam, and air conditioning; water supply, sewerage, and waste management and remediation activities; construction; wholesale and retail trade, and repair of motor vehicles and motorcycles; transportation and storage; accommodation and food service activities; information and communication; financial and insurance activities; real estate activities; professional, scientific, and technical activities).

A high degree of standardisation and cross-cultural validation of measures among the countries participating characterises the CIS and makes it suitable as data source for the purpose of this study due to the comparability of the results. Furthermore, as described by Eurostat's corresponding Synthesis Quality Report, data quality meets high research standards.

We also employ Hofstede scores of the five cultural dimensions, available on Geert Hofstede's website (www.geert-hofstede.com) or in Hofstede et al. (2010). Finally, we apply five indicators accounting for institutional and economic conditions at the country level that may impact firm's innovation behaviour. These factors are institutions, higher education and training, labour market efficiency, financial market development, and technological readiness, with their definitions and operationalisations derived from the Global Competitiveness Report 2008-2009 published by the World Economic Forum.

As we combine measures from various sources, we do not consider common method and response bias a serious problem for this study. Table A.1 in Appendix A a detailed definition of the variables used for the empirical analysis. Table 1 contains variable means, standard deviations, and Pearson correlations. 


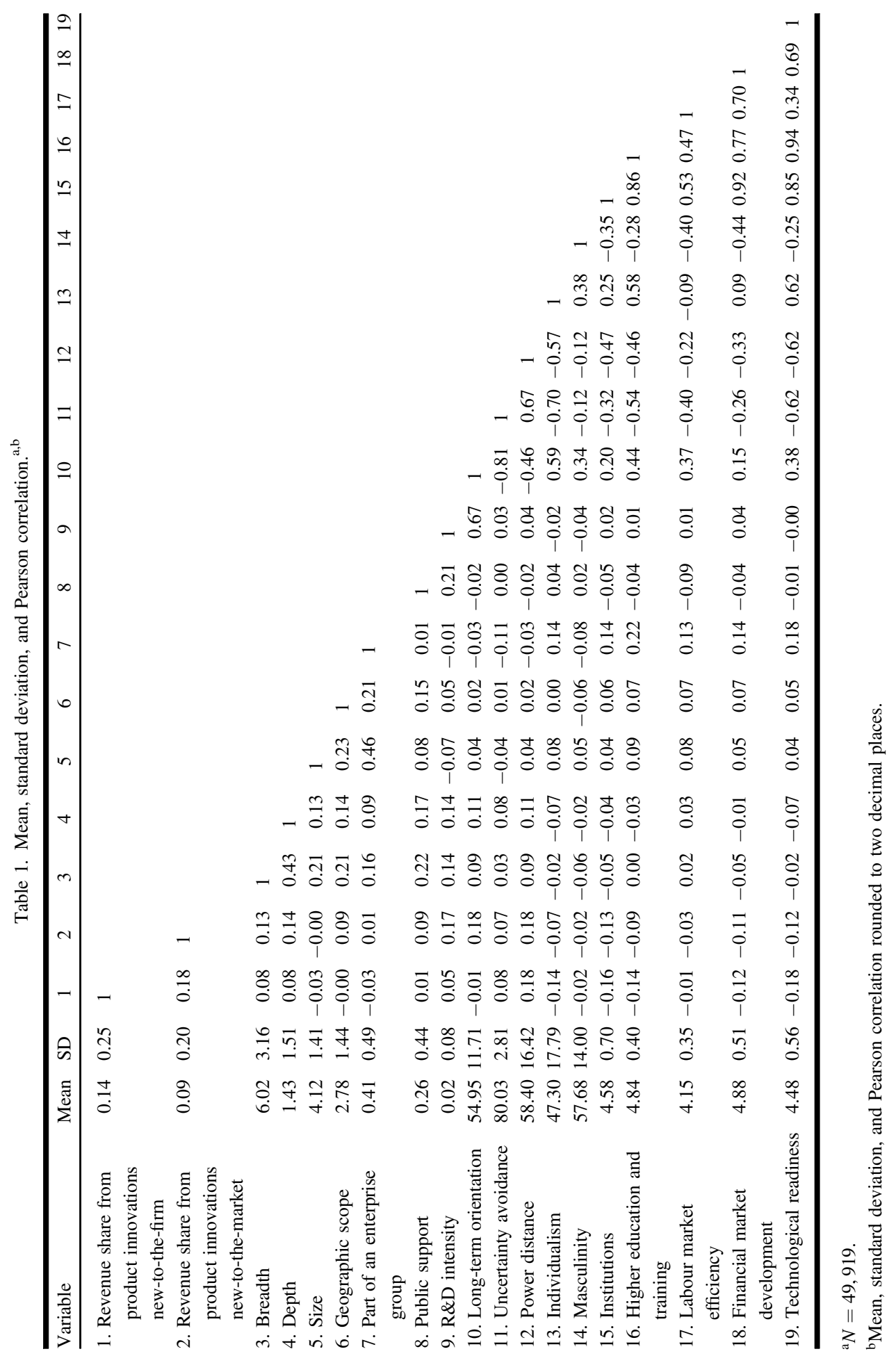




\section{Econometric strategy}

The dependent variable (i.e., the revenue proportions of (i) product innovations new-to-the-market, and (ii) product innovations new-to-the-firm) is by definition bounded between 0 and 1. We follow the suggestions of Papke and Wooldridge (1996) and Ramalho et al. (2011) for modelling the logistic conditional mean specification

$$
E(y \mid x)=\frac{e^{x \theta}}{1+e^{x \theta}},
$$

and the corresponding link function

$$
h(E(y \mid x))=\ln \left(\frac{\frac{e^{x \theta}}{1+e^{x \theta}}}{1-\frac{e^{x \theta}}{1+e^{x \theta}}}\right),
$$

where $y$ is the fractional variable, $x$ is a vector of covariates, and $\theta$ is the vector of parameters to be estimated. In accordance with the previously presented theoretical reasoning, our one-part model a priori assumes the same data generation process for all observed values within the interval. The model is estimated via quasi-maximum likelihood (QML).

\section{Tests of hypotheses}

The first two columns of Table 2 present the results of the baseline fractional regression model, focusing on the main effects for explaining innovative performances regarding innovations new-to-the-market and new-to-the-firm, respectively. For both innovation types, the parameter for breadth is significant and positive, while breadth squared is significant and negative. This result provides support for Hypothesis 1a, which predicts a curvilinear (inverted U-shaped) relationship between innovative performance and search breadth.

Consistent with Hypothesis $1 \mathrm{~b}$, we find an analogous relationship between search depth and performance regarding innovations new-to-the-market. For innovations new-to-the-firm, however, only the parameter for depth, not for depth squared, proves significant; this points to a rather linear relationship. In line with theoretical arguments and empirical evidence provided by Laursen and Salter (2006), our results suggest a stronger effect of search depth on radical innovation than on incremental innovation.

Regarding the direct influence of national culture on innovation performance, all Hofstede dimensions show significant main effects on both innovation types. Both types benefit from low scores of uncertainty avoidance and masculinity, and high scores of power distance and long-term orientation. Radical innovation is 


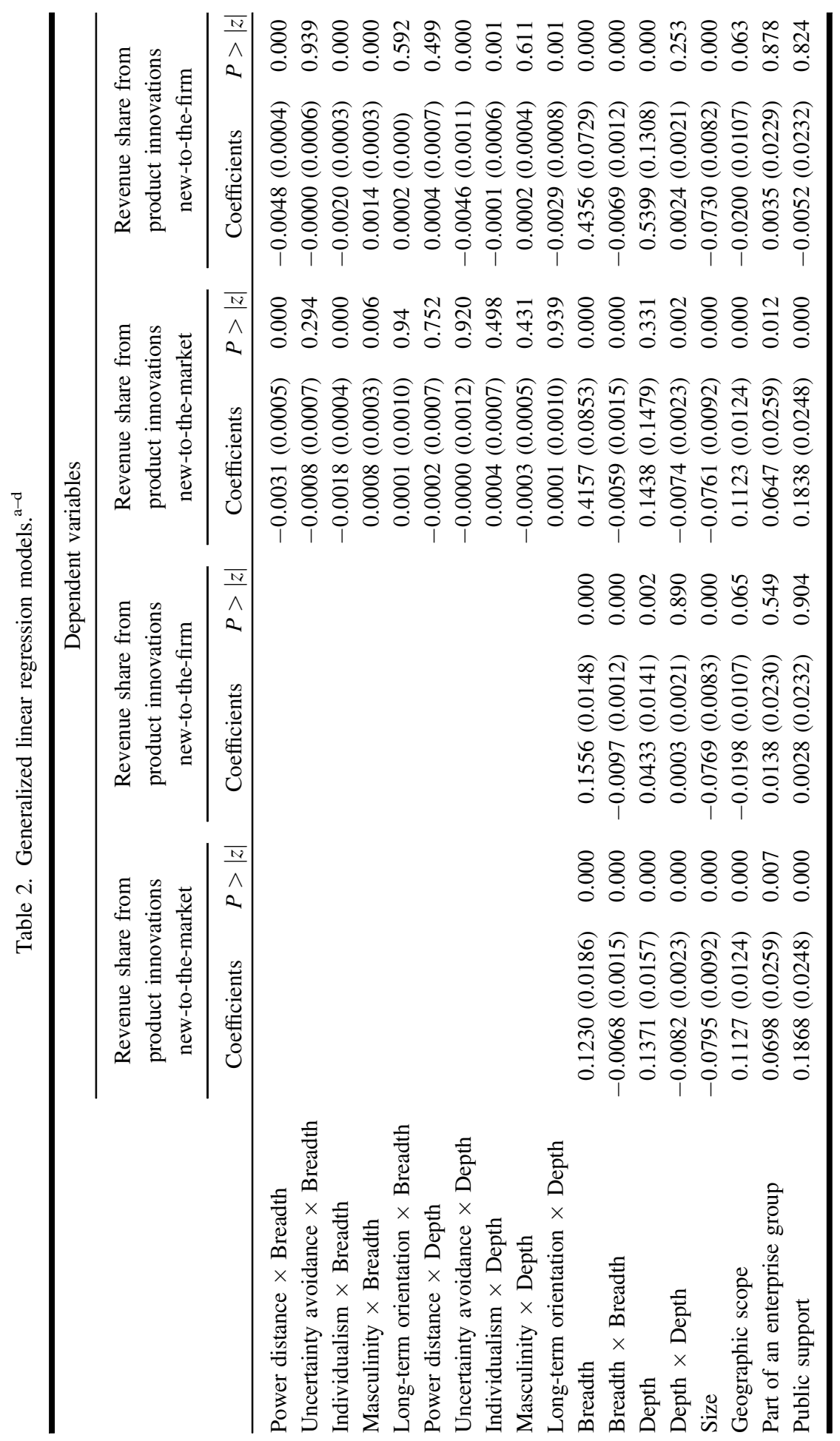




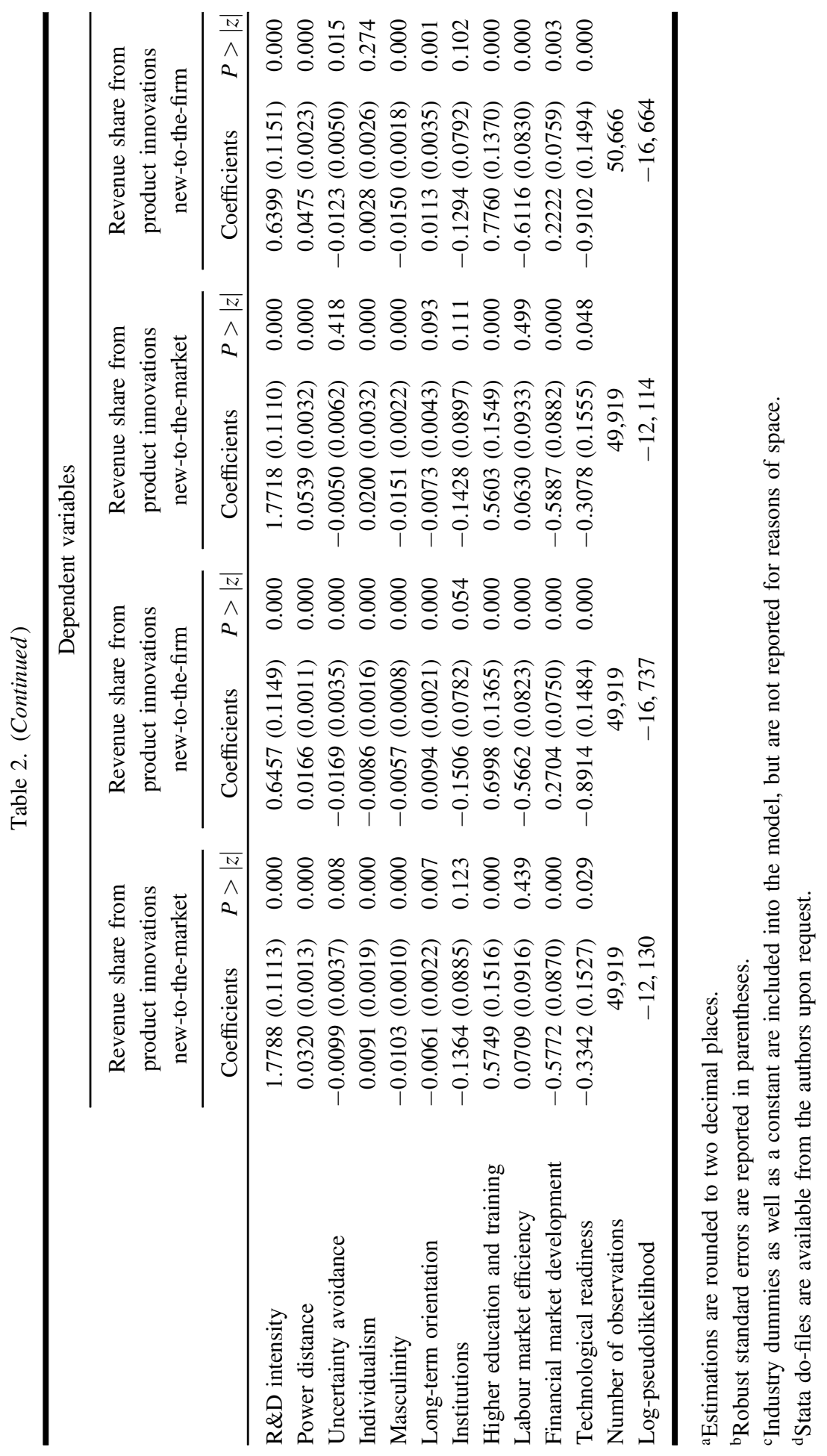


furthermore related to high values of individualism, whereas for incremental innovation the opposite relationships hold.

As regards firm-level controls, a number of factors exert influence on innovation performance. R\&D intensity has by far the largest positive effect on both innovation types; firm size is negatively associated with innovation performance. Public support seems to be relevant only for innovations new-to-the-market. An extensive geographic scope of market activities is related to a firm's inclination to introduce innovations new-to-the-market, whereas a more domestic orientation has a weakly positive influence on incremental innovation.

The estimates laid out in the right two columns of Table 2 include interaction effects between search breadth and depth and the cultural dimensions. In line with expectations and corroborating Hypotheses $3 \mathrm{a}$ and $4 \mathrm{a}$, we find highly significant negative interaction effects between external search breadth and individuality and the power distance scores, respectively, for both innovation types. Quite in contrast to our prediction, however, masculinity turns out to increase the positive effect of search breadth on innovative performance. This contradicts Hypothesis 2a.

For external search depth, we can only determine a significant negative interaction effect with individualism for product innovations new-to-the-firm, which provides mixed support for Hypothesis $3 \mathrm{~b}$. Moderating effects of power distance and masculinity on the relationship between external search depth and innovation performance prove not significant. Hypotheses $2 b$ and $4 b$ therefore do not receive support from the empirical evidence.

\section{Discussion}

\section{Revisiting the theoretical considerations}

Examining the role of openness in explaining innovation performance for a largescale sample comprising firms from various European countries, our study finds the curvilinear relationships of external search breadth and depth with innovative performance are essentially universal, holding across various cultural and institutional contexts as well as for different types of innovation with only one exception. This insight countervails an unambiguous trend to opening up firms' innovation processes, but suggests that there is an optimal degree of openness beyond which further integration of external knowledge sources becomes unproductive.

In economic interpretation, this result points to an underlying trade-off between specific benefits and costs accruing to external knowledge sourcing. While the benefits are spelled out by the open innovation literature, our understanding of the 
specific costs and risks of open innovation strategies is still underdeveloped (Dahlander and Gann, 2010; Lichtenthaler, 2011). Although the theoretical discussion has provided some tentative reasoning about the cost side of the equation, further research is required to more precisely track down the tipping point beyond which firms are 'over-searching' and 'over-cooperating'.

In this regard, an important result of our study is the finding that the optimal degree of openness is not a 'universal constant' but depends on the firm-specific context. The country culture in which the firm's operations are embedded is an important part of this context. Several cultural dimensions are identified as significantly influential on the effectiveness of a firm's search behaviour. Somewhat surprisingly, this effect pertains predominantly to the breadth of search activities; depth proves less affected by the cultural context. A possible explanation for this result suggests that a country's culture more strongly influences more casual and less institutionalised knowledge-based relations. When knowledge exchange deepens and interaction intensifies, shared understandings, fixed patterns of collaborations, and institutionalised processes develop, arguably substituting for the moderating effect of cultural values at the country level.

While the moderating effects of power distance and individuality on the relationship between search breadth and innovation performance accord with our theoretically informed expectations, the effect of masculinity is somewhat puzzling. A possible explanation refers to the observation that organisations in masculine cultures emphasise training and improvement of the individual (Hofstede, 1980). The education of the workforce, which can be seen as a corollary to these values of training and self-improvement, again is an important determinant of the firm's absorptive capacity (e.g., Cohen and Levinthal, 1989, 1990; Zahra and George, 2002). By fostering the absorptive capacity of firms, a masculine culture thus may facilitate the transfer and assimilation of external knowledge which is a critical factor for the success of inbound open innovation strategies. Further research, however, is required to corroborate this tentative reasoning and to sort out the complex set of relationships the masculinity dimension apparently entertains with firms' innovation behaviour.

\section{Theoretical, managerial, and political implications}

In terms of theoretical implications, our results underscore urgent calls to develop a contingency perspective on open innovation strategies that some authors launched after reviewing the state of the field (Huizingh, 2011; Lichtenthaler, 2011). Such perspective must not be confined to considering firm- and industrylevel characteristics, but should also include country-level attributes. Furthermore, integrating such contingency factors at various levels of analysis also 
requires researchers to account for their numerous and complex interaction effects. Our results show cultural factors immediately impact innovative performance and simultaneously interact with search breadth and depth as further determinants of innovative success (first-order interaction effects), but also probably interact with further moderating factors (second-order interaction effects), and so on.

The high degree of causal complexity these interrelations entail brings methodological challenges of its own. Configurational analysis could offer a pragmatic way to organise such complex and interdependent cause-effect relationships into coherent accounts explaining variance in firm's innovation behaviour and performance (Ganter and Hecker, 2014). As configurational analysis integrates multiple causal relationships into a small number of typified profiles, it allows "to combine complexity with parsimony" (Fiss, 2011:294). To further develop theoretical understanding on that matter, we suggest extending a contingency towards a configurational perspective on open innovation.

For managers, our findings imply the need to account for cultural factors when devising innovation strategy. As R\&D activities become increasingly global and managers' degree of freedom for choosing their location increases, they should carefully consider the fit between the planned innovation strategy and the country culture before making a location decision (Jones and Davis, 2000; Nakata and Sivakumar, 1996). Specifically, our results suggest that countries exhibiting low power distance, low individualism, and high masculinity provide the best support for inbound open innovation strategies and broad R\&D collaborations.

Furthermore, managers operating in multinational enterprises must recognise and accommodate cultural peculiarity and diversity. Approaches and practices of innovation management proven in one country may not be easily transferred to another without adaptation to the new environment. Innovation strategy and supporting internal institutions (e.g., training programmes) should be crafted in compatibility with the prevailing set of cultural values. Multinational enterprises are well advised to keep innovation policies sufficiently flexible to accommodate cross-border differences in innovation activities' antecedents. These might include decoupling innovation processes and practices for different countries (e.g., Ansari et al., 2010; Kostova and Roth, 2002; Newman and Nollen, 1996).

For policy makers, our study highlights cultural values as a source of competitive advantage at the country level. They endow nations with a specific innate (or at least inert), non-tradable resource that represents an important innovation input. As different types of innovation strategy vary in cultural contingencies, a shift in the dominating innovation strategy archetypes (e.g., from closed towards open strategies) may entail a shift in the comparative advantage of countries as a location for R\&D and innovation. Countries could turn cultural idiosyncrasies into 
comparative advantage by specialising their innovation efforts on the types and strategies best adapted to their cultural endowment.

This suggestion extends a point already made by some earlier studies comparing the innovation systems in the US and Japan. These studies argue that while the individualistic and risk tolerant US culture supports more radical product innovation, Japan holds a comparative advantage for incremental and processoriented innovations from its collectivistic and uncertainty avoiding culture (e.g., Freeman, 1987; Herbig and Miller, 1992). Our results suggest that such alignment could be relevant for far more comprehensive typologies of innovation strategies also incorporating various degrees of openness.

\section{Limitations}

When considering the results and implications of our study, it is also important to note some of its limitations. A first caveat arises from the scope of the data, and the fact that the sample is restricted to European countries. To enhance the generalisability of our findings, data from further countries (possibly exhibiting even greater cultural diversity) should be analysed and incorporated.

More fundamental, perhaps, are some concerns about the construct and measurement of culture. Although we build on one of the best-established and validated approaches, the Hofstede framework also earns critiques for several reasons. Detractors especially question its completeness with respect to all relevant aspects of a country's culture. Alternative approaches have, in fact, shown the pertinence of additional and alternative cultural dimensions (e.g., House et al., 2004; Inglehart, 1997; Leung et al., 2005; Schwartz, 2004). Taking these other studies into account, we do not claim this study exhaustively explores cultural traits and their influence on open innovation strategy. Its results do show, however, that the cultural dimensions Hofstede elicited significantly impact firm's innovation behaviour, and therefore corroborate the explanatory and predictive content of this framework (Minkov and Hofstede, 2011). Subsequent studies may extend these findings by undertaking consideration for additional cultural traits and dimensions.

A related issue pertains to the question of whether a comparison at the country level is the most adequate level of cultural analysis at all, and whether national boundaries are truly consistent with cultural boundaries. Without doubt there are substantial cultural variations within a country (e.g., between regions or social groups such as occupations, social strata, and religious communities). Researching cultural diversity and its impact on firm behaviour at various levels of analysis therefore yields a much more complete picture of culture's consequences on economic activity (Peterson and Søndergaard, 2011; Tsui et al., 2007). Nevertheless, our results illustrate significant variance of cultural values across countries 
even in such a relatively institutionally harmonised economic area such as Europe. They also reveal that these cultural differences do significantly impact the effectiveness of open innovation strategies. National culture thus represents an important contingency for innovation management, and should be integrated as building block into a comprehensive contingency or configurational approach to the topic.

Pursuing this line of thought, firms are not only influenced by the culture of their surrounding society, but can develop their own corporate culture. Analogous to country culture, corporate culture refers to a set of values and beliefs that firm employees share, and that guides their behaviour and action (Denison, 1990; Schein, 1992). Corporate culture has likewise been shown to have important effects on firms' innovation behaviour and success (Herzog and Leker, 2010; Tellis et al., 2009). Important questions of the culture-innovation debate pertain to the comparative effects of culture at the country- and firm-level on the effectiveness of a firm's search strategy regarding external knowledge, as well as to the (possible) degree of divergence between corporate and national cultures (Gerhart, 2009; Nelson and Suresh, 2003). Unfortunately, in the empirical setting of this study, we lack the data to explicitly consider and control for the characteristics and influence of corporate culture. Cross-level research integrating the cultural context at the firm- and country-level and examining the interplay of cultural factors at both levels in shaping firm-level innovation processes and outcomes promises an exciting and illuminating wave in future research.

To conclude, innovation management can indeed be judged culturally dependent. The local cultural context enables and constrains innovation strategies. For best results, innovation strategies and practices should exploit the comparative advantages inherent in a country's culture. This important insight emerging from this study will hopefully guide further innovation research and management effort.

\section{Appendix A}

Table A.1. Variable operationalisation.

Variable

Dependent variables

Revenue share from

product or service

innovations

new-to-the-market
Scale level

Definition

Proportion Proportion of revenue in 2008 attributable to innovations between 2006 and 2008 that are new-to-the-market. 
Table A.1. (Continued)

\begin{tabular}{l} 
Variable \\
\hline Revenue share from \\
product or service \\
innovations \\
new-to-the-firm
\end{tabular}

\section{Independent variables}

Breadth

\section{Depth}

Ordinal

Size

Interval

Geographic scope

Ordinal
Scale level

Definition

Proportion

Proportion of revenue in 2008 attributable to innovations between 2006 and 2008 that are only new-to-the-firm.

Following Laursen and Salter (2006), this variable is operationalised as the sum of the number of information sources a company utilised between 2006 and 2008 ranging from 0 (if no source was used) to 10 (if all of the following sources were applied): (i) "within enterprise"; (ii) "suppliers of equipment, materials, components, or software"; (iii) "clients or customers"; (iv) "competitors or other enterprises in your sector"; (v) "consultants, commercial labs, or private R\&D institutes"; (vi) "universities or other higher education institutes"; (vii) "government or public research institutes"; (viii) "conferences, trade fairs, and exhibitions"; (ix) "scientific journals and trade/technical publications; (x) "professional and industry associations".

Following Laursen and Salter (2006), this variable is operationalised as the sum of the number of information sources judged to be highly important to the innovation process between 2006 and 2008 ranging from 0 (if no source was evaluated as highly important) to 10 (if all of the following sources were rated highly important): (i) "within enterprise"; (ii) "suppliers of equipment, materials, components, or software"; (iii) "clients or customers"; (iv)

"competitors or other enterprises in your sector"; (v) "consultants, commercial labs, or private R\&D institutes"; (vi) "universities or other higher education institutes"; (vii) "government or public research institutes"; (viii) "conferences, trade fairs, and exhibitions"; (ix) "scientific journals and trade/ technical publications; (x) "professional and industry associations".

Log of the average number of employees (including apprentices and interns) in 2008.

The value is 1 for only local or regional sales markets, and it is 2 if the market scope is limited to the respective country. If the sales markets only comprise EU countries, EFTA countries, or EU candidate 
Table A.1. (Continued)

\begin{tabular}{|c|c|c|}
\hline Variable & Scale level & Definition \\
\hline & & $\begin{array}{l}\text { countries, the value is } 3 \text {. If the geographical scope of } \\
\text { the coverage of sales activities goes beyond, the value } \\
\text { is } 4 \text {. }\end{array}$ \\
\hline $\begin{array}{l}\text { Part of an enterprise } \\
\text { group }\end{array}$ & Binary & $\begin{array}{l}\text { Value is } 1 \text { if a company belongs to an enterprise group, } \\
\text { and } 0 \text { if not. }\end{array}$ \\
\hline Public support & Binary & $\begin{array}{l}\text { The value is } 1 \text { if a firm receives support through state } \\
\text { ministries or federal ministries or the European } \\
\text { Union; } 0 \text { otherwise. }\end{array}$ \\
\hline$R \& D$ intensity & Ordinal & $\begin{array}{l}\text { If a company conducts } R \& D \text { steadily, this variable takes } \\
\text { on the value } 2 \text {. It takes on the value } 1 \text { if } R \& D \text { is } \\
\text { carried out occasionally, and } 0 \text { if it is essentially not } \\
\text { performed at all. }\end{array}$ \\
\hline Power distance & Ordinal & $\begin{array}{l}\text { This dimension is defined as the acceptance of inequality } \\
\text { by less powerful members of the society; score ranges } \\
\text { between } 1 \text { and } 120 \text { (Hofstede, 2001). }\end{array}$ \\
\hline Uncertainty avoidance & Ordinal & $\begin{array}{l}\text { This dimension is defined as "the tolerance for } \\
\text { ambiguity"; score ranges between } 1 \text { and } 120 \\
\text { (Hofstede, 2001). }\end{array}$ \\
\hline Individualism & Ordinal & $\begin{array}{l}\text { This dimension is defined as the "degree to which people } \\
\text { in a society are integrated into groups"; scores ranges } \\
\text { between } 1 \text { and } 120 \text { (Hofstede, 2001). }\end{array}$ \\
\hline Masculinity & Ordinal & $\begin{array}{l}\text { This dimension is defined as the "distribution of values } \\
\text { between the genders"; score ranges between } 1 \text { and } \\
120 \text {. }\end{array}$ \\
\hline Long-term orientation & Ordinal & $\begin{array}{l}\text { This dimension describes a society's time horizon and its } \\
\text { relationships to the past and future; score ranges } \\
\text { between } 1 \text { and } 120 \text { (Hofstede, 2001). }\end{array}$ \\
\hline Technological readiness & & $\begin{array}{l}\text { The degree to which an economy uses technology } \\
\text { already available is described by this variable and is } \\
\text { captured on a scale between } 1 \text { and } 7 \text { (see p. } 5 \text { of } \\
\text { Global Competitiveness Report } 2008-2009 \text { ). } \\
\text { Methodological issues are described at the Global } \\
\text { Competitiveness Report } 2008-2009 \text { published by the } \\
\text { World Economic Forum. }\end{array}$ \\
\hline $\begin{array}{c}\text { Financial market } \\
\text { development }\end{array}$ & Ordinal & $\begin{array}{l}\text { The degree to which an economy allocates resources to } \\
\text { its most productive use is referred to as financial } \\
\text { market development and is captured on a scale } \\
\text { between } 1 \text { and } 7 .^{\text {a }}\end{array}$ \\
\hline Institutions & Ordinal & $\begin{array}{l}\text { The quality of public and private institutions including } \\
\text { the legal framework, administrative efficiency, and } \\
\text { accounting and reporting standards is captured on a } \\
\text { scale between } 1 \text { and } 7 . \text { b }\end{array}$ \\
\hline
\end{tabular}


Table A.1. (Continued)

\begin{tabular}{|c|c|c|}
\hline Variable & Scale level & Definition \\
\hline $\begin{array}{l}\text { Higher education and } \\
\quad \text { training }\end{array}$ & Ordinal & $\begin{array}{l}\text { This variable reflects secondary and tertiary education, } \\
\text { educational quality, and staff training on a scale } \\
\text { between } 1 \text { and } 7 .^{\text {a }}\end{array}$ \\
\hline Labor market efficiency & Ordinal & $\begin{array}{l}\text { The efficiency of labour markets is defined as the extent } \\
\text { of the allocation of labour to the most productive use } \\
\text { on a scale between } 1 \text { and } 7 .^{\text {a }}\end{array}$ \\
\hline Industry & Binary & $\begin{array}{l}\text { Industry dummies (IS) are included for } 58 \text { industry } \\
\text { segments (NACE Rev. } 2 \text { code). }\end{array}$ \\
\hline
\end{tabular}

a(see p. 5 of Global Competitiveness Report 2008-2009).

b(see p. 4 of Global Competitiveness Report 2008-2009).

\section{References}

Ahuja, G (2000). Collaboration networks, structural holes, and innovation: A longitudinal study. Administrative Science Quarterly, 45(3), 425-455.

Alexander, EA (2012). The effects of legal, normative, and cultural-cognitive institutions on innovation in technology alliances. Management International Review, 52(6), 791-815.

Ansari, SM, PC Fiss and EJ Zajac (2010). Made to fit: How practices vary as they diffuse. Academy of Management Review, 35(1), 67-92.

Aslesen, HW and M Freel (2012). Industrial knowledge bases as drivers of open innovation? Industry and Innovation, 19(7), 563-584.

Barge-Gil, A (2010). Open, semi-open and closed innovators: Towards an explanation of degree of openness. Industry and Innovation, 17(6), 577-607.

Barge-Gil, A (2013). Open strategies and innovation performance. Industry and Innovation, 20(7), 585-610.

Barney, JB and MH Hansen (1994). Trustworthiness as a source of competitive advantage. Strategic Management Journal, 15, 175-190.

Chen, CC, X-P Chen and JR Meindl (1998). How can cooperation be fostered? The cultural effects of individualism-collectivism. Academy of Management Review, 23 (2), 285-304.

Chen, X-P and S Li (2005). Cross-national differences in cooperative decision-making in mixed-motive business contexts: The mediating effect of vertical and horizontal individualism. Journal of International Business Studies, 36(6), 622-636.

Chesbrough, HW (2003). Open Innovation: The New Imperative for Creating and Profiting from Technology. Cambridge, MA: Harvard Business School Press.

Cohen, WM and DA Levinthal (1989). Innovation and learning: The two faces of R\&D. Economic Journal, 99(397), 569-596. 


\section{A. Hecker}

Cohen, WM and DA Levinthal (1990). Absorptive capacity: A new perspective on learning and innovation. Administrative Science Quarterly, 35(1), 128-152.

Cox, TH, SA Lobel and PL McLeod (1991). Effects of ethnic group cultural differences on cooperative and competitive behavior on a group task. Academy of Management Journal, 34(4), 827-847.

Dahlander, L and DM Gann (2010). How open is innovation? Research Policy, 39(6), 699-709.

Denison, DR (1990). Corporate Culture and Organizational Effectiveness. New York, NY: John Wiley \& Sons.

Dyer, JH and H Singh (1998). The relational view: Cooperative strategy and sources of interorganizational competitive advantage. Academy of Management Review, 23(4), 660-679.

Earley, PC (1989). Social loafing and collectivism: A comparison of the United States and the People's Republic of China. Administrative Science Quarterly, 34(4), 565-581.

Enkel, E, O Gassmann and H Chesbrough (2009). Open R\&D and open innovation: Exploring the phenomenon. $R \& D$ Management, 39(4), 311-316.

Fey, CF and J Birkinshaw (2005). External sources of knowledge, governance mode, and R\&D performance. Journal of Management, 31(4), 597-621.

Fiss, PC (2011). Building better causal theories: A fuzzy set approach to typologies in organizational research. Academy of Management Journal, 54(2), 393-420.

Foss, NJ, K Laursen and T Pedersen (2011). Linking customer interaction and innovation: The mediating role of new organizational practices. Organization Science, 22(4), 980-999.

Freeman, C (1987). Technology Policy and Economic Performance: Lessons from Japan, London: Pinter Publishers.

Ganter, A and A Hecker (2014). Configurational paths to organizational innovation: Qualitative comparative analyses of antecedents and contingencies. Journal of Business Research, 67(6), 1285-1292.

Gassmann, O (2006). Opening up the innovation process: Towards an agenda. $R \& D$ Management, 36(3), 223-228.

Gassmann, O, E Enkel and $\mathrm{H}$ Chesbrough (2010). The future of open innovation. $R \& D$ Management, 40(3), 213-221.

Gelfand, MJ, M Erez and Z Aycan (2007). Cross-cultural organizational behavior. Annual Review of Psychology, 58(1), 479-514.

Gerhart, B (2009). How much does national culture constrain organizational culture? Management and Organization Review, 5(2), 241-259.

Hayton, JC, G George and SA Zahra (2002). National culture and entrepreneurship: A Review of behavioral research. Entrepreneurship Theory and Practice, 26(4), $33-52$.

Herbig, PA and JC Miller (1992). Culture and technology: Does the traffic move in both directions. Journal of Global Marketing, 6(3), 75-104. 
Herzog, P and J Leker (2010). Open and closed innovation: Different innovation cultures for different strategies. International Journal of Technology Management, 52(3-4), 322-343.

Hofstede, G (1980). Culture's Consequences: International Differences in Work Related Values. Newbury Park, CA: Sage Publications.

Hofstede, G (2001). Culture's Consequences: Comparing Values, Behaviors, Institutions, and Organizations across Nations. Thousand Oaks, CA: Sage Publications.

Hofstede, G, GJ Hofstede and M Minkov (2010). Cultures And Organizations: Software of the Mind. New York, NY: McGraw-Hill.

House, RJ, PJ Hanges, M Javidan, PW Dorfman and V Gupta (eds.) (2004). Culture, Leadership, and Organizations: The GLOBE Study of 62 Societies. Thousand Oaks, CA: Sage Publications.

Huizingh, EKRE (2011). Open innovation: State of the art and future perspectives. Technovation, 31(1), 2-9.

Inglehart, R (1997). Modernization and Postmodernization: Cultural, Economic, and Political Change in 43 Societies. Princeton, NJ: Princeton University Press.

Jones, GK and HJ Davis (2000). National culture and innovation: Implications for locating global R\&D operations. Management International Review, 40(1), 11-39.

Kirkman, BL, KB Lowe and CB Gibson (2006). A quarter century of culture's consequences: A review of empirical research incorporating Hofstede's cultural values framework. Journal of International Business Studies, 37(3), 285-320.

Kostova, T and K Roth (2002). Adoption of an organizational practice by subsidiaries of multinational corporations: Institutional and relational effects. Academy of Management Journal, 45(1), 215-233.

Laursen, K and A Salter (2006). Open for innovation: The role of openness in explaining innovation performance among U.K. manufacturing firms. Strategic Management Journal, 27(2), 131-150.

Leung, K, RS Bhagat, NR Buchan, M Erez and CB Gibson (2005). Culture and international business: Recent advances and their implications for future research. Journal of International Business Studies, 36(4), 357-378.

Lichtenthaler, U (2011). Open innovation: Past research, current debates, and future directions. Academy of Management Perspectives, 25(1), 75-93.

Minkov, M and G Hofstede (2011). The evolution of Hofstede's doctrine. Cross Cultural Management, 18(1), 10-20.

Nakata, C and K Sivakumar (1996). National culture and new product development: An integrative review. Journal of Marketing, 60(1), 61-72.

Nelson, RE and G Suresh (2003). Do organizational cultures replicate national cultures? Isomorphism, rejection and reciprocal opposition in the corporate values of three countries. Organization Studies, 24(7), 1115-1151.

Newman, KL and SD Nollen (1996). Culture and congruence: The fit between management practices and national culture. Journal of International Business Studies, 27(4), 753-779. 


\section{A. Hecker}

Papke, LE and JM Wooldridge (1996). Econometric methods for fractional response variables with an application to 401(k) plan participation rates. Journal of Applied Econometrics, 11(6), 619-632.

Peterson, MF and M Søndergaard (2011). Traditions and transitions in quantitative societal culture research in organization studies. Organization Studies, 32(11), $1539-1558$.

Png, IPL and BCY Tan (2001). Dimensions of national culture and corporate adoption of IT infrastructure. IEEE Transactions on Engineering Management, 48(1), $36-45$.

Rigby, D and C Zook (2002). Open-market innovation. Harvard Business Review, 80(10), 80-89.

Ramalho, EA, JS Ramalho and JR Murteira (2011). Alternative estimating and testing empirical strategies for fractional regression models. Journal of Economic Surveys, 25(1), 19-68.

Schein, EH (1992). Organizational Culture and Leadership. San Francisco, CA: JosseyBass.

Schwartz, SH (2004). Mapping and interpreting cultural differences around the world. In Comparing Cultures: Dimensions of Culture in a Comparative Perspective, H Vinken, J Soeters and P Ester (eds.), pp. 43-73. Leiden, The Netherlands: Brill.

Shane, S (1993). Cultural influences on national rates of innovation. Journal of Business Venturing, 8(1), 59-73.

Shane, S, S Venkataraman and I MacMillan (1995). Cultural differences in innovation championing strategies. Journal of Management, 21(5), 931-952.

Steenkamp, J-BEM, F ter Hofstede and M Wedel (1999). A cross-national investigation into the individual and national cultural antecedents of consumer innovativeness. Journal of Marketing, 63(2), 55-69.

Steensma, HK, L Marino, KM Weaver and PH Dickson (2000a). The influence of national culture on the formation of technology alliances by entrepreneurial firms. Academy of Management Journal, 43(5), 951-973.

Steensma, HK, L Marino and KM Weaver (2000b). Attitudes toward cooperative strategies: A cross-cultural analysis of entrepreneurs. Journal of International Business Studies, 31(4), 591-609.

Tellis, GJ, JC Prabhu and RK Chandy (2009). Radical innovation across nations: The preeminence of corporate culture. Journal of Marketing, 73(1), 3-23.

Tether, BS and A Tajar (2008). Beyond industry-university links: Sourcing knowledge for innovation from consultants, private research organisations and the public sciencebase. Research Policy, 37(6-7), 1079-1095.

Tomlinson, PR (2010). Co-operative ties and innovation: Some new evidence for UK manufacturing. Research Policy, 39(6), 762-775.

Tsui, AS, SS Nifadkar and AY Ou (2007). Cross-national, cross-cultural organizational behavior research: Advances, gaps, and recommendations. Journal of Management, 33(3), 426-478. 
van de Vrande, V, JPJ de Jong, W Vanhaverbeke and M de Rochemont (2009). Open innovation in SMEs: Trends, motives and management challenges. Technovation, 29(6-7), 423-437.

van de Vrande, V, C Lemmens and W Vanhaverbeke (2006). Choosing governance modes for external technology sourcing. $R \& D$ Management, 36(3), 347-363.

van de Vrande, V, W Vanhaverbeke and O Gassmann (2010). Broadening the scope of open innovation: Past research, current state and future directions. International Journal of Technology Management, 52(3-4), 221-235.

van Everdingen, YM and E Waarts (2003). The effect of national culture on the adoption of innovations. Marketing Letters, 14(3), 217-232.

Zahra, SA and G George (2002). Absorptive capacity: A review, reconceptualization, and extension. The Academy of Management Review, 27(2), 185-203. 